\title{
Corrigendum: Effects of Fiscal Decentralization on Garbage Classifications
}

\author{
Qiuzhuo Ma ${ }^{1}$, Diejun Huang ${ }^{2 *}$, Hua $\mathrm{Li}^{3}$, Yimei Hu${ }^{4}$, Krishna P. Paudel ${ }^{5}$, Sijin Zhang ${ }^{1}$ and \\ Jianfeng Zhang ${ }^{1}$
}

${ }^{1}$ Business School, Guangdong University of Foreign Studies, Guangzhou, China, ${ }^{2}$ Institute of Geography and Tourism, Guangdong University of Finance and Economics, Guangzhou, China, ${ }^{3}$ College of Economics and Management, South China Agricultural University, Guangzhou, China, ${ }^{4}$ Aalborg University Business School, Aalborg University, Aalborg, Denmark, ${ }^{5}$ LSU Agricultural Center, Louisiana State University, Baton Rouge, LA, United States

Keywords: garbage classification, fiscal decentralization, quantitative analysis, optimization, rural area

\section{A corrigendum on}

Effects of Fiscal Decentralization on Garbage Classifications by Ma, Q., Huang, D., Li, H., Hu, Y., Paudel, K. P., Zhang, S., and Zhang, J. (2021). Front. Energy Res. 9:686561. doi: 10.3389/fenrg.2021.686561

\section{OPEN ACCESS}

Approved by:

Frontiers Editorial Office, Frontiers Media SA, Switzerland

${ }^{*}$ Correspondence: Diejun Huang diejunhuang@gdufe.edu.cn

Specialty section: This article was submitted to Sustainable Energy Systems and

Policies,

a section of the journal Frontiers in Energy Research

Received: 11 January 2022 Accepted: 25 January 2022 Published: 18 February 2022

Citation:

Ma Q, Huang D, Li H, Hu Y, Paudel KP, Zhang $S$ and Zhang J (2022) Corrigendum: Effects of Fiscal Decentralization on Garbage Classifications. Front. Energy Res. 10:852351. doi: $10.3389 /$ fenrg.2022.852351
In the original article, we neglected to include some funding sources from the department who funds the research that relates to a wide range of natural science researches in Guangdong province. Grant number 2018A030310687 to Natural Science Foundation of Guangdong Province, and number 2019A1515012149 to Natural Science Foundation of Guangdong Province are now added to the Funding statement. The updated Funding statement can be found below.

\section{FUNDING}

This work was supported by Philosophy and Social Science Planning Project of Guangdong Province, grant no: GD19CYJ14, The department who funds the research that relates to a wide range of social researches; Natural Science Foundation of Guangdong Province, grant no: 2018A030310687 and 2019A1515012149, The department who funds the research that relates to a wide range of natural science researches in Guangdong province.

The authors apologize for this error and state that this does not change the scientific conclusions of the article in any way. The original article has been updated.

Publisher's Note: All claims expressed in this article are solely those of the authors and do not necessarily represent those of their affiliated organizations, or those of the publisher, the editors and the reviewers. Any product that may be evaluated in this article, or claim that may be made by its manufacturer, is not guaranteed or endorsed by the publisher.

Copyright $\odot 2022 \mathrm{Ma}$, Huang, Li, Hu, Paudel, Zhang and Zhang. This is an open-access article distributed under the terms of the Creative Commons Attribution License (CC BY). The use, distribution or reproduction in other forums is permitted, provided the original author(s) and the copyright owner(s) are credited and that the original publication in this journal is cited, in accordance with accepted academic practice. No use, distribution or reproduction is permitted which does not comply with these terms. 